\title{
Finding a New Identity
}

\author{
Geon Ho Bahn \\ Department of Psychiatry, Kyung Hee University School of Medicine, Seoul, Korea
}

It seems like only yesterday that I started my job as editor-in-chief (EIC) of the Journal of the Korean Academy of Child and Adolescent Psychiatry (JKACAP) in January 2016 and asked the boards of Korean Academy of Child and Adolescent Psychiatry (KACAP) to extend the term of EIC from two to five years. In a few days, the 20th issue, my last one as your editor, will be published. With having an offline meeting for the editorial committee every two months and publishing an issue every three months, my life over the past five years has been geared to the publication of the JKACAP. All I could think about was how I could use my activities, including patient care, family life, business trips, and even leisure activities, for the journal. During the 6th World Congress on ADHD in Vancouver, Canada in April 2017, I visited the Museum of Anthropology at the University of British Columbia. In the legend of the statue on display, I read that the frog in the statue was the communicator between mother Earth and mankind, and thought it would be nice to have a frog that connects JKACAP with the readers. On the return flight, I wrote an editorial "Communicator frog, to be a catcher or a frog itself" [1]. When I returned from Zero to Three Annual Conference in San Diego at the end of November 2017, I bought the biography of Leonardo da Vinci by Walter Isaacson, which had been published very recently, and read it for more than 10 hours during the flight, completing the first draft of a book review for the JKACAP [2].

There have been many changes in the JKACAP over the past five years, as shown in "The Thirty-First Year Journey" [3], a special article to celebrate the 31st anniversary of JKACAP. To earn these achievements, KACAP boards have trusted and supported the editorial committee, and on behalf of the editorial committee, I am deeply grateful. In particular, I express my gratitude to Yoo-Sook Joung (president of KACAP during 2016-2017) for supporting the construction of a website for JKACAP and for the preparation involved in transitioning to an English journal, to Bong-Seog Kim (president of KACAP during 2018-2019) for launching a Task Force (TF) for the purpose of globalization and brand enhancement and

This is an Open Access article distributed under the terms of the Creative Commons Attribution Non-Commercial License (https://creativecommons.org/licenses/by-nc/4.0) which permits unrestricted non-commercial use, distribution, and reproduction in any medium, provided the original work is properly cited. for supporting the conversion to an exclusively English-language journal, and to current president Dongwon Shin, who has shown faith in the process of changing the journal. Changing the framework and language of the journal from Korean to English is like Margaret Mahler's separation-individuation process-breaking the existing mother-child relationship and building a new identity. To be separated and individuated, it needs a repetition of destruction and reconstruction, and serious instability may occur in the process. In addition to anxieties from this repetitive process, financial support is needed to change the identity of the journal, and it is therefore burdensome to push for it. Thus, the editorial titles in 2016, my first year as EIC, continued to be ambivalent: "Grasp all, lose all" [4]; "Comfortable armchair" or "Entrust ourselves to the waves?" [5]. As time passed, with strong support from KACAP, JKACAP could complete its own identity in the second half of 2016, "I hope that the choice to take the 'road not taken' instead of taking 'the one already traveled' is beneficial and helpful for everyone"[6]. The result is the publication of two issues in two days: volume 27, issue 4 on December 31, 2016; volume 28, issue 1 on January 1,2017. By advancing the publication month and date, we expected to make it easier for readers to receive and utilize new knowledge. In the process of individuation, separation anxiety and the fear of failure continued to wriggle and disrupt the process. I was in search of places to lean on: "Tips from BTS" [7]; relying on "Ghosts of Christmas" [8]. With the help of colleagues and the encouragement of the members of KACAP, individuation and identity creation continued: "To be a bridge over troubled water" [9]; "Reckless frog in the well” [10]; "One small step, but one giant leap for the JKACAP” [11]; "To expand the scope of child mental health professionals to both personal and global levels" [12]. Even with the COVID-19 pandemic, JKACAP is moving forward: "From the COVID-19 pandemic into a brave new world" [13].

At the end of my term, I remember more difficult memories than pleasant ones, especially the authors of rejected or unpublished papers and tasks that remained incomplete. If there are people who resent me for publishing the articles, please accept my apologies with generosity. I do hope you will continue to love JKACAP. I sincerely thank all the members 
of the editorial committee, especially professor Young-Sook Kwack, Tae Won Park, and Jung-Woo Son, for their attendance and smiles during five years of frequent offline meetings and reconstructions of this journal. I always felt a familial warmth towards the people of Raum and Inforang, who helped me as by taking on the journal's responsibilities as their own. I also appreciate Daniel Fung, Yukiko Kano, Sandra Kooij, Say How Ong, Takuya Saito, Tjhin Wiguna, Yesie Yoon, and Yi Zheng for their willingness to participate in the development of JKACAP, and I ask for their continued interest and support. I am extremely grateful to Minha Hong, who was the assistant editor during my term as EIC and tirelessly helped me rectify errors to perfection.

One of the things that developed during my term was that the EIC and editor-elect attended an offline committee meeting every two months for one year as a transition period, giving the editor-elect a chance to naturally take over and learn about the journal's affairs. While working together, I recognized that professor Jae Hyun Yoo, assistant editor-elect, is a hidden gem who sheds light on the future of the editorial committee. Min-Hyeon Park, team leader of the TF for globalization and brand enhancement of the JKACAP, probably doesn't notice that she was born for this job. I am comfortable with passing the term of the EIC because I am familiar with the passion and infectious energy of editor-elect Hee Jeong Yoo.

Once again, I express my deep gratitude and respect to the board members of KACAP for their financial and emotional support and for the faith that helped me serve as EIC. Personally, I thank my family. My wife and kids were willing to allow me to devote more time and effort towards JKACAP than on housework because they know how much I like this job. I hope that JKACAP will continue to develop through all our efforts and that the academic papers published in the journal can be used to promote child and adolescent mental health.

\section{REFERENCES}

1) Bahn GH. Communicator frog, to be a catcher or a frog itself. J Korean Acad Child Adolesc Psychiatry 2017;28:155.

2) Bahn GH. Leonardo da Vinci. J Korean Acad Child Adolesc Psychiatry 2019;30:45-47.

3) Yoo HJ, Park MH, Yoo JH, Hong M, Bahn GH. The thirty-first year journey, the Journal of the Korean Academy of Child and Adolescent Psychiatry. J Korean Acad Child Adolesc Psychiatry 2020;31: 201-206.

4) Bahn GH. 'Killing Two Birds with One Stone' or 'Grasp All, Lose All'. J Korean Acad Child Adolesc Psychiatry 2016;27:99.

5) Bahn GH. 'Comfortable Armchair' or 'Entrust Ourselves to the Waves?' J Korean Acad Child Adolesc Psychiatry 2016;27:163.

6) Bahn GH. Mission accomplished. J Korean Acad Child Adolesc Psychiatry 2017;28:45.

7) Bahn GH. Tips from BTS. J Korean Acad Child Adolesc Psychiatry 2017;28:191.

8) Bahn GH. Answer comes from the ghost of christmas past, present, and yet to come. J Korean Acad Child Adolesc Psychiatry 2018; 29:1.

9) Bahn GH. To be a "Bridge Over Troubled Water". J Korean Acad Child Adolesc Psychiatry 2018;29:87.

10) Bahn GH. Reckless frog in the well. J Korean Acad Child Adolesc Psychiatry 2018;29:149.

11) Bahn GH. One small step, but one giant leap for the Journal of the Korean Academy of Child and Adolescent Psychiatry. J Korean Acad Child Adolesc Psychiatry 2019;30:87.

12) Bahn GH. To expand the scope of child mental health professionals to both personal and global levels. J Korean Acad Child Adolesc Psychiatry 2019;30:133.

13) Bahn GH. From COVID-19 pandemic into a brave new world. J Korean Acad Child Adolesc Psychiatry 2020;31:49-50. 